\title{
Efecto de la adición de materia orgánica sobre la dinámica poblacional bacteriana del suelo en cultivos de papa y maíz
}

\author{
Effect of addition of organic matter on bacterial population dynamics of \\ soil in potato and corn crops
}

\section{David García Ventocilla1, Gloria Mamani Gamarra1, Nicolás Román Cabello, Luis Suárez Salas ${ }^{2}$, Ana Contreras Marín ${ }^{2}$, Julio Malca Jauregui ${ }^{2}$}

\begin{abstract}
1 Instituto de Biotecnología e Ingeniería Genética - Universidad Nacional del Centro del Perú. Ciudad Universitaria, Av. Mariscal Cludad Universitaria, Av. Mariscal Castilla No 3909 - 4089, El Tambo, Email David Garcia Ventocilla: d2_gv@hotmail.com 2 Instituto de Investigaciones para el Desarrollo Tecnológico (ININDETEC)
\end{abstract}

\section{Resumen}

Se determinó el efecto de la fertilización orgánica sobre las poblaciones bacterianas del suelo en cultivos de papa y maíz durante la campaña agrícola 2008-2009 en terrenos de cuatro localidades del Valle del Mantaro: INIA Santa Ana (Huancayo), en la EEA EI Mantaro (Jauja), Vista Alegre y Huayao (ambos en Chupaca). En estos lugares se instalaron parcelas experimentales de papa (Solanum tuberosum L. Var. Canchan) y maíz (Zea maíz L. Var. Cusco mejorado) bajo abonamiento orgánico (vacuno, ovino, cuy), fertilización química y sin fertilización alguna (testigo). Para dicho efecto se empleó las técnicas de la Electroforesis en Gel de Gradiente Desnaturalizante (DGGE) con amplificación de la región 968 - 1401 del rDNA 16S. Los resultados obtenidos muestran que la variabilidad de las poblaciones bacterianas en los suelos está afectado directamente por el tipo de cultivo mas no por el tipo de fertilización ya que el efecto de este último resulta variable para cada zona experimental y cultivo encontrándose solo en la zona experimental de Chupaca - Maíz una segregación de los tratamientos con fertilización orgánica de los tratamientos químicos. También se ha encontrado que la variación de las comunidades microbianas no sufre variaciones significativas en los suelos con cultivos de maíz obteniéndose coeficientes de similaridad para todos los tratamientos por encima del $80 \%$ mientras que para los tratamientos en los cultivos de papa dicho coeficiente fue de tan solo del $60 \%$.

Palabras clave: Materia orgánica, papa, maíz, DGGE.

\section{Abstract}

The effect of organic fertilization on soil bacterial populations in potato and corn crops during the crop season 2008-2009 at four sites in the Mantaro Valley locations: INIA Santa Ana (Huancayo), the EEA EI Mantaro (Jauja), Vista Alegre and Huayao (both in Chupaca). In these places were set up experimental plots of potato (Solanum tuberosum L. var. Canchan) and corn (Zea maize L. Var. Cusco enhanced) under organic manure (cattle, sheep, guinea pig), chemical fertilizer and no fertilizer at all (control). To do this we used the techniques of electrophoresis Denaturing Gradient Gel (DGGE) with amplification of the region from 968 to 1401 of $16 S$ rDNA. The results show that the variability of bacterial populations in soil is directly affected by crop type but not by the type of fertilization and the effect of the latter is variable for each experimental area and culture found only in the experimental area of Chupaca - Corn segregation of treatments with organic fertilization of chemical treatments. We have also found that the variation of the microbial communities did not suffer significant variations in soils with maize similarity coefficients obtained for all treatments above $80 \%$ while for the treatments in potato crops that rate was only $60 \%$.

Keywords: Organic matter, potato, corn, DGGE.

\section{Introducción}

Se considera que entre el 80 y $90 \%$ de los procesos que ocurren en los suelos, son reacciones mediadas por los microorganismos (Nannipieri et al. 2003). Los microorganismos han sido descritos como el motor de los ecosistemas terrestres (Killham 1994), dado su papel en la mineralización y transformación de la materia orgánica, además de influir directamente en el metabolismo de las plantas, ya que también fijan nitrógeno, producen metabolitos, actúan como controladores biológicos e inclusive pueden descomponer productos tóxicos (Azevedo 1998), también ayudan a mantener la estructura del suelo, ya que actúan como agentes cementantes que estabilizan los agregados del mismo (Elliott et al. 1996). Es por ello que la biomasa microbiana toma un papel crítico en todos los ecosistemas naturales y manipulados por el hombre. Algunas prácticas agrícolas pueden producir alteraciones críticas en la comunidad microbiana del suelo. Una de estas prácticas es el uso de excesivos fertilizantes inorgánicos y pesticidas que causan cambios en las densidades de hongos y bacterias, la supresión o la promoción del crecimiento, y la actividad microbiana. Estos cambios pueden contribuir a la pérdida de la diversidad y o función de la comunidad microbiana (Heilmann et al. 1995, Girvan et al. 2004). En cuanto a las prácticas agrícolas que influyen positivamente en el mantenimiento de la calidad de los suelos, tenemos el uso de la materia orgánica como fertilizante, la cual mejora las diversas propiedades del suelo como la capacidad de intercambio cationico, retención del agua y estructura del suelo, pero el aporte probablemente mayor de este tipo de fertilización es el desarrollo y promoción de una gran actividad biológica (Felipe-Morales 2002).

Dado a estos antecedentes el objetivo de este estudio fue determinar el efecto del tipo de fertilización orgánica sobre la distribución bacteriana en los suelos al finalizar los cultivos de papa y maíz. Para ello se empleó las técnicas de la Electroforesis en Gel de Gradiente Desnaturalizante (DGGE), técnica ampliamente utilizada en ecología microbiana para determinar la composición y estructura de comunidades microbianas dominantes permitiendo estudiar las comunidades microbianas en términos ecológico moleculares definidos por el número y/o forma de la distribución del material genético extraído de las poblaciones bacterianas directamente del suelo (Garbeva et al. 2004). 


\section{Material y métodos}

\section{Áreas de estudio y recolección de muestras}

La investigación se realizó durante la campaña agrícola 20082009 en terrenos de cuatro localidades del Valle del Mantaro: INIA Santa Ana (Huancayo), en la EEA El Mantaro (Jauja), Vista Alegre y Huayao (ambos en Chupaca). Los análisis fisicoquímicos se realizaron en el Laboratorio de Análisis de Suelos, Aguas y Plantas (LASAP) y el análisis molecular para evaluar el efecto de fertilización orgánica sobre las poblaciones bacterianas en el suelo se realizaron en los laboratorios del Instituto de Biotecnología e Ingeniería Genética (IBIG), ambos pertenecientes a la Universidad Nacional del Centro del Perú.

Se instalaron parcelas experimentales de papa (Solanum tuberosum L. Var. Canchan) y maíz (Zea maíz L. Var. Cusco mejorado) en las cuatro zonas anteriormente mencionadas bajo abonamiento orgánico (ovino (T1), cuy (T2), vacuno (T3)), fertilización química (T4) y sin fertilización alguna (testigo, T5). La cantidad de estiércol fue de 15 t.ha $^{-1}$ para cultivo de papa y de 10 t.ha ${ }^{-1}$ para cultivo de maíz. Las dosis de fertilizante químico fueron de 0,180 - 0,120 - 0,080 tm.ha-1 de N-P-K, respectivamente (Ver tabla 1 ).

Tabla 1. Dosis de abono orgánico y fertilizante químico aplicadas a cada cultivo. Tratamientos: T1: ovino, T2: cuy, T3: vacuno, T4: fertilización química N-P-K: (T4), Testigo: T5.

\begin{tabular}{cccccc}
\hline & \multicolumn{5}{c}{$\mathrm{tm} \mathrm{ha}^{-1} ; \mathrm{n}=3$} \\
\hline Zona & $\mathrm{T} 1$ & $\mathrm{~T} 2$ & $\mathrm{~T} 3$ & $\mathrm{~T} 4$ & $\mathrm{~T} 5$ \\
\hline Huayao & 10 & 10 & 10 & $0,18-0,12-0,08$ & 0 \\
Mantaro & 10 & 10 & 10 & $0,18-0,12-0,08$ & 0 \\
Santa Ana & 10 & 10 & 10 & $0,18-0,12-0,08$ & 0 \\
Chupaca & 10 & 10 & 10 & $0,18-0,12-0,08$ & 0 \\
\hline & & & & Papa & \\
\hline Huayao & 15 & 15 & 15 & $0,18-0,12-0,08$ & 0 \\
Mantaro & 15 & 15 & 15 & $0,18-0,12-0,08$ & 0 \\
Santa Ana & 15 & 15 & 15 & $0,18-0,12-0,08$ & 0 \\
Chupaca & 15 & 15 & 15 & $0,18-0,12-0,08$ & 0 \\
\hline
\end{tabular}

Los análisis se realizaron antes del experimento y al final de los cultivos. La instalación de las parcelas experimentales siguió un diseño de bloques completamente randomizado con tres repeticiones por tratamiento. Se cogieron $100 \mathrm{~g}$ de suelo entre plantas de cada repetición y cada tratamiento, para ello se empleó una pequeña lampa, la cual sirvió para remover la parte superficial del suelo tomando de esta manera la alícuota a una profundidad aproximada entre 5 y $10 \mathrm{~cm}$.

Las muestras recolectadas fueron trasladadas en refrigeración al laboratorio para el procesamiento de las mismas que consistió en la eliminación del exceso de humedad, tamizado en mallas de $2 \mathrm{~mm}$ de tamaño de luz y mezcla de las tres muestras de un mismo tratamiento para obtener una sola muestra representativa, la cual sirvió para los análisis respectivos. Las muestras para los análisis moleculares se almacenaron a $-40{ }^{\circ} \mathrm{C}$.
Optimización de las condiciones de desarrollo de la electroforesis en geles de gradiente desnaturalizante.

\section{Extracción y purificación de DNA microbiano de suelo}

Se evaluaron tres métodos de extracción de DNA microbiano a partir muestras de suelo. Estos métodos corresponden a las metodologías empleadas por Seishi et al. (2004), Quirino et al. (2006) y Griffiths et al. (2000), las cuales fueron adaptadas a las condiciones del laboratorio en cuanto a equipamiento e insumos en algunos casos. Para la purificación del DNA se hizo uso de los kits "Wizard DNA Clean - Up System" de la empresa comercial Promega USA y "AxyPrep Multisource DNA Mini" de la empresa comercial Axigen USA. Tanto la concentración y pureza de DNA fueron determinados mediante visualización en geles de agarosa.

\section{Amplificación de la región 968 - 1401 del rDNA $16 S$}

Para la amplificación de la región 968-1401 del rDNA 16S se empleó los iniciadores $968 \mathrm{~F}$ - 1401R y el kit GoTaq DNA Polymerase (catalogo\#: M3005). Se probaron 12 programas en las que se variaron temperaturas y tiempos de alineamiento, además se experimentaron con 12 concentraciones diferentes de insumos de PCR tales como $\mathrm{MgCl} 2$, dNTPs, Taq, y primers.

\section{Electroforesis en geles de gradiente desnaturalizante (DGGE)}

Se preparó geles de polacrilamida al $6 \%(\mathrm{w} / \mathrm{v})$ con gradiente de desnaturalización de 40-70\% (urea - formamida). Para la formación del gradiente y corrida de los geles se hizo uso del sistema de electroforesis vertical Denaturing Gradiente Gel Electophoresis System 2001 de la empresa C.B.S. Scientific Compay, Inc. En este equipo se evaluó el tiempo y el voltaje a aplicar en la corrida para la obtención de bandas con la resolución deseada. La temperatura y buffer de corrida empleado en todos los casos fue de $60^{\circ} \mathrm{C}$ y TAE $0.5 \mathrm{X}$ respectivamente. Para la tinción de los geles se empleó el protocolo para tinción de geles de poliacrilamida con nitrato de plata propuesta por Embrapa solos (2004).

\section{Efecto de la adición de la materia orgánica en la diversidad poblacional bacteriana del suelo}

Los perfiles de bandas que se obtuvieron a partir de las corridas electroforéticas (DGGE) fueron convertidos en una matriz binaria de acuerdo a la presencia o ausencia de bandas. Esta matriz fue procesada en el software NTSYSpc 2.1 con coeficiente de similaridad DICE y agrupado con el algoritmo UPGMA.

\section{Resultados y discusión}

Optimización de las condiciones de desarrollo de la electroforesis en geles de gradiente desnaturalizante

De los resultados de la evaluación de los métodos para la extracción de DNA del suelo, se optó por la metodología propuesta por Quirino et al. (2006), debido a que se obtiene DNA de buena calidad y sin presencia de RNA con peso de aproximadamente 12000 bp visualizados en gel de agarosa al 1\%, cuyo valor coincide al que reporta Silva (2004) y Bresolin (2006).

Del proceso de estandarización de la PCR para la amplificación de la región de 968 - 1401 del rDNA 16S se logró obtener amplificados satisfactorios con el siguiente programa y formulación: desnaturalización inicial de 3 min a $94^{\circ} \mathrm{C} ; 35$ 
ciclos (desnaturalización $94^{\circ} \mathrm{C}$ x $1 \mathrm{~min}$; alineamiento: $58^{\circ} \mathrm{C}$ x 1 min; polimerización: $72^{\circ} \mathrm{C} \times 1 \mathrm{~min}$ ); extensión final de $10 \mathrm{~min}$ a $72^{\circ} \mathrm{C}$. La concentración de los insumos de la PCR fueron: dNTPs: 0,2 mM; $\mathrm{MgCl}_{2}: 0 \mathrm{mM}$; Green GoTaq Buffer: 1X; 968 (forward): 0,5 $\mu$; 1401 (reverse): 0,5 $\mu \mathrm{M}$; GoTaq DNA polymerasa: $0,025 \mathrm{U} / \mu \mathrm{L}$.

Para las corridas de los geles DGGE se determinó que a las 20 horas, a $70 \mathrm{~V} \mathrm{y} 60^{\circ} \mathrm{C}$ se obtienen bandas con la separación y resolución adecuada para la interpretación de los geles.

En el proceso de extracción y purificación de DNA microbiano de las muestras de suelo de los tratamientos para cada lugar y cultivo se pudo apreciar bandas con intensidades diferentes, esto debido probablemente a la cantidad de material extraído y origen de estas según lo reporta Silva (2004). De este último se resalta la pobre extracción de DNA de las muestras provenientes de zona experimental de Santa Ana, logrando extraer DNA a partir de los suelos con tratamientos T1, T3 y T4 con cultivos de papa y T5 con cultivos de maíz. Esto presumiblemente a la disminución de la concentración de las poblaciones bacterianas debido a la acidificación y salinización de los suelos en cultivos de maíz (Tabla 2 y 3).

En cuanto a la amplificación de la región 968 - 1401 de las muestras de DNA extraído se obtuvo bandas con peso aproximado de 450 bp presentando intensidades adecuadas para el empleo de la técnica del DGGE. Estos resultados coinciden con lo reportado por Bresolin (2006).

Efecto de la adición de la materia orgánica en la diversidad poblacional bacteriana del suelo

\section{Poblaciones bacterianas antes de la instalación de los cultivos}

Los suelos de las zonas experimentales de Huayao y Chupaca presentaron poblaciones bacterianas muy similares cuyo
Tabla 2. Propiedades, químicas del suelo en las cuatro localidades experimentales antes de aplicar los tratamientos. (Noviembre de 2008). Fosforo (P), Conductividad Eléctrica (CE), Carbonato de calcio $(\mathrm{CaCO} 3)$.

\begin{tabular}{lccccc}
\hline $\begin{array}{c}\text { Localidad } \\
\text { Suelo }\end{array}$ & Trat. & $\mathbf{p H}$ & $\mathbf{P}$ & $\mathbf{C E}$ & $\mathbf{C a C O}_{3}$ \\
& & & $\mathbf{( p p m )}$ & $\mathbf{d S} / \mathbf{m}$ & $\mathbf{\%}$ \\
\hline Chupaca & T1 & 8,03 & 21,62 & 0,324 & 2,34 \\
& T2 & 8,07 & & 0,424 & 2,34 \\
& T3 & 8,02 & & 0,394 & 2,56 \\
& T4 & 8,00 & & 0,325 & 2,45 \\
& T5 & 8,04 & & 0,356 & 2,46 \\
\hline Santa Ana & T1 & 6,02 & 23,97 & 0,157 & - \\
& T2 & 5,94 & & 0,132 & - \\
& T3 & 6,00 & & 0,103 & - \\
& T4 & 6,03 & & 0,106 & - \\
& T5 & 6,18 & & 0,106 & - \\
\hline Mantaro & T1 & 7,37 & 46,35 & 0,176 & 0,37 \\
& T2 & 7,42 & & 0,186 & 0,35 \\
& T3 & 7,29 & & 0,275 & 0,23 \\
& T4 & 7,55 & & 0,163 & 0,45 \\
& T5 & 7,87 & & 0,195 & 0,46 \\
\hline Huayao & T1 & 7,52 & 43,41 & 0,420 & 0,74 \\
& T2 & 8,06 & & 0,459 & 1,34 \\
& T3 & 7,55 & & 0,465 & 1,34 \\
& T4 & 7,84 & & 0,435 & 2,30 \\
& T5 & 7,87 & & 0,643 & 2,46 \\
\hline & & & & & \\
\hline
\end{tabular}

coeficiente de similaridad (CS) alcanzó un máximo del 65\%. Además estos suelos albergaron a una gran cantidad de especies bacterianas representados por el número de bandas presentes en los geles DGGE (Muyzer \& Smalla 1998), encontrándose 64 y 50 bandas para los suelos de Huayao y Chupaca respectivamente. En los suelos del El Mantaro y Santa Ana el número de bandas presentes fue mucho menor (21 para Mantaro y 20 para Santa

Tabla 3. Variación real de los valores correspondientes a las propiedades físico-químicas del suelo en las cuatro localidades experimentales al final de los cultivos de papa y maíz tratados con cinco tipos de abonamiento. Fosforo (P), Conductividad Eléctrica (CE).

\begin{tabular}{|c|c|c|c|c|c|c|c|}
\hline \multirow[t]{2}{*}{ Localidad/suelo } & \multirow[t]{2}{*}{ Trat. } & \multicolumn{3}{|c|}{ Cultivo de papa } & \multicolumn{3}{|c|}{ Cultivo de maíz } \\
\hline & & $\mathrm{pH}$ & $\begin{array}{c}P \\
(\mathrm{ppm})\end{array}$ & $\begin{array}{c}\mathrm{CE} \\
\mathrm{dS} / \mathrm{m}\end{array}$ & $\mathrm{pH}$ & $\begin{array}{c}P \\
\text { (ppm) }\end{array}$ & $\begin{array}{c}\mathrm{CE} \\
\mathrm{dS} / \mathrm{m}\end{array}$ \\
\hline \multirow[t]{5}{*}{ Chupaca } & $\mathrm{T} 1$ & $-0,03$ & 84,28 & 0,560 & 0,37 & 106,50 & $-0,106$ \\
\hline & $\mathrm{T} 2$ & 0,03 & 71,08 & 0,530 & 0,43 & 59,22 & $-0,222$ \\
\hline & $\mathrm{T} 3$ & 0,08 & 69,48 & 0,393 & 0,48 & 65,05 & $-0,195$ \\
\hline & $\mathrm{T} 4$ & $-0,10$ & 75,08 & 0,471 & 0,50 & 90,91 & 0,046 \\
\hline & $\mathrm{T} 5$ & 0,16 & 72,88 & 0,440 & 0,46 & 65,05 & $-0,159$ \\
\hline \multirow[t]{5}{*}{ Santa Ana } & $\mathrm{T} 1$ & 0,08 & 24,93 & 0,213 & $-0,42$ & 22,86 & 0,214 \\
\hline & $\mathrm{T} 2$ & 0,36 & 17,53 & 0,149 & $-0,34$ & 34,27 & 0,393 \\
\hline & $\mathrm{T} 3$ & 0,00 & 26,63 & 0,252 & $-0,30$ & 50,82 & 0,304 \\
\hline & $\mathrm{T} 4$ & $-0,63$ & 16,53 & 0,237 & $-0,43$ & 27,28 & 0,224 \\
\hline & T5 & $-0,48$ & 16,33 & 0,122 & $-0,68$ & 14,24 & 0,317 \\
\hline \multirow[t]{5}{*}{ Mantaro } & $\mathrm{T} 1$ & $-0,07$ & 31,25 & 0,144 & 0,73 & $-13,61$ & 0,090 \\
\hline & $\mathrm{T} 2$ & $-0,12$ & 29,35 & 0,117 & 0,78 & 17,63 & 0,066 \\
\hline & $\mathrm{T} 3$ & 0,01 & 27,95 & 0,067 & 0,81 & 19,75 & $-0,009$ \\
\hline & $\mathrm{T} 4$ & $-0,25$ & $-0,35$ & 0,265 & 0,25 & 25,03 & 0,056 \\
\hline & $\mathrm{T} 5$ & $-0,57$ & 19,55 & 0,097 & 0,23 & $-19,32$ & 0,062 \\
\hline \multirow[t]{5}{*}{ Huayao } & $\mathrm{T} 1$ & 0,38 & 45,09 & $-0,010$ & 0,68 & 8,08 & $-0,156$ \\
\hline & $\mathrm{T} 2$ & $-0,06$ & 24,59 & $-0,087$ & 0,24 & 16,40 & $-0,204$ \\
\hline & T3 & 0,35 & 13,99 & $-0,065$ & 0,75 & 36,13 & $-0,218$ \\
\hline & $\mathrm{T} 4$ & 0,06 & 25,39 & 0,081 & 0,46 & 24,65 & $-0,176$ \\
\hline & $\mathrm{T} 5$ & 0,03 & 5,29 & $-0,242$ & 0,33 & $-7,34$ & $-0,382$ \\
\hline
\end{tabular}




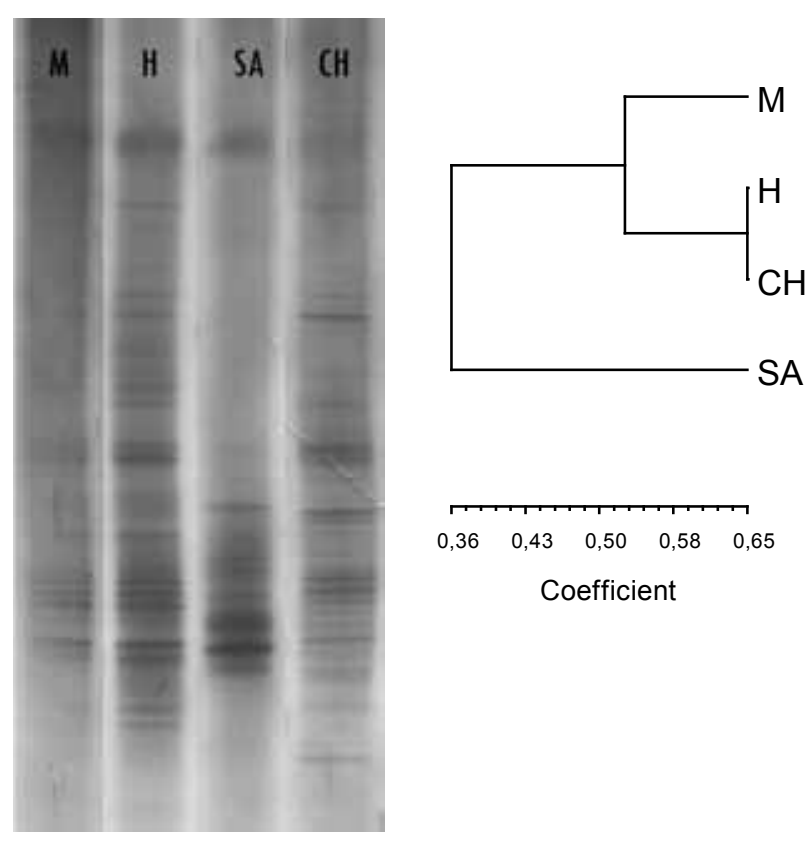

Figura 1. A: Fotografia de Gel $16 \mathrm{~S}$ rDNA-DGGE de muestras recolectadas antes de la instalación de los cultivos. Mantaro (M), Huayao $(\mathrm{H})$, Chupaca $(\mathrm{CH})$, Santa Ana (SA). B: Dendograma respectivo de la figura 1.a generado por el algoritmo UPGMA y coeficiente de similaridad DICE.

Ana) resaltando poblaciones bacterianas diferentes de la zona experimental de Santa Ana en comparación de las demás zonas experimentales. Esto se observa en la Figura 1B donde la similaridad de las poblaciones bacterianas de las muestras de suelo de Santa Ana se separan del resto formando un grupo con una similaridad del 36\%. De estos resultados se evidencia la pobre fertilización biológica encontrada en los suelos experimentales del El Mantaro y Santa Ana.

\section{Poblaciones bacterianas después de la siembra}

Chupaca.- En los suelos donde se desarrollaron los cultivos de papa se encontró un coeficiente de similaridad máximo del $89 \%$ para los tratamientos T2 y T4. Esto nos indica que ambos tratamientos favorecen el desarrollo de poblaciones bacterianas similares. También se puede observar que los grupos T5-T3 y T1-T2-T3 proporcionan poblaciones bacterianas con una similaridad del $79 \%$ cuyo valor es un indicativo de la no variación dramática en cuanto al manejo de los suelos con diferentes opciones de fertilización. En cuanto a la riqueza de especies bacterianas representadas por el número de bandas presentes en los geles DGGE se encontró que los tratamientos T1, T3 y T5 generaron la mayor cantidad de bandas $(55,53$ y 50 bandas respectivamente), mientras que los tratamientos $\mathrm{T} 2$ y $\mathrm{T} 4$ fueron los que produjeron el menor número de bandas ( 43 y 42 bandas respectivamente). También se pudieron apreciar bandas únicas en los tratamientos T1, T3 y T5 (5, 5 y 3 bandas respectivamente).

En los suelos en donde se desarrollaron los cultivos de maíz se encontró un CS máximo del $93 \%$ para los tratamientos T1 y T3 y un CS mínimo del 83\% entre los grupos T1-T3-T2 y T4-T5. Estos valores difieren dramáticamente a los obtenidos en los suelos con cultivo papa, mostrando una relación directa entre la distribución de las poblaciones bacterianas versus la fertilización orgánica, la no fertilización y la fertilización química. En cuanto a la riqueza de especies bacterianas se encontró que el tratamiento T5 genera una cantidad un poco mayor de bandas ( 47 bandas) comparado a los demás tratamientos que produjeron 44, 44, 42 y 43 en los tratamientos T1, T2, T3 y T4 respectivamente. En cuanto a la producción de bandas únicas el T5 produjo 4 bandas únicas, mientras que el T1, T2 y T4 produjeron 2, 2 y 1 banda respectivamente. El T3 es el único que no presenta bandas únicas.

Mantaro.- En los suelos en donde se desarrollaron los cultivos de papa se encontró un CS máximo del $96 \%$ para los tratamientos T4 y T5. Los grupos T3 y T1-T2-T4-T5 proporcionan poblaciones bacterianas con una similaridad del $78 \%$. En cuanto a la riqueza de especies bacterianas, los tratamientos $\mathrm{T} 1, \mathrm{~T} 2, \mathrm{~T} 4$ y T5 generaron la mayor cantidad de bandas $(30,31,33$ y 34 bandas respectivamente), mientras que el tratamiento T3 un número de bandas menor ( 22 bandas). Solo el tratamiento T4 produjo una banda inédita.

En los suelos en donde se desarrollaron los cultivos de maíz se encontró un CS máximo del $98 \%$ para los tratamientos T3 y T4 y un CS mínimo del 88\% entre los grupos T5 y T1-T2T3-T4 mostrando una relación directa entre la distribución de poblaciones bacterianas versus la fertilización y la no fertilización. En cuanto a la riqueza de especies bacterianas se encontró que los tratamientos T3 y T4 presentaron un número mayor de bandas (32 y 31 bandas respectivamente) comparado a los tratamientos $\mathrm{T} 1$, T2 y $\mathrm{T} 5$ que produjeron 27,27 y 23 bandas respectivamente. El T3 fue el único que produjo una banda única.

Huayao.- En los suelos donde se desarrollaron los cultivos de papa se encontró un CS máximo del $74 \%$ para los tratamientos T1 y T3. Los grupos T2 y T1-T3 proporcionan poblaciones bacterianas con una similaridad del $78 \%$. En cuanto a la riqueza de especies bacterianas, los tratamientos $\mathrm{T} 1, \mathrm{~T} 2, \mathrm{~T} 3$ generaron 19, 23 y 19 bandas con 2, 7 y 3 bandas únicas respectivamente.

En los suelos en donde se desarrollaron los cultivos de maíz se encontró un CS máximo del 94\% para los tratamientos T1 y T4 y un CS mínimo del 80\% entre los grupos T2 y T1-T4-T5 mostrando una relación directa entre la distribución de poblaciones bacterianas versus la fertilización y la no fertilización. En cuanto a la riqueza de especies bacterianas, los tratamientos $\mathrm{T} 1$, T2, T4 y T5 generaron $25,19,25$ y 23 bandas con $0,1,1,0$ bandas únicas respectivamente.

Santa Ana.- En los suelos en donde se desarrollaron los cultivos de papa se encontró un CS máximo del $70 \%$ para los tratamientos T1 y T4. Los grupos T3 y T1-T4 proporcionan poblaciones bacterianas con una similaridad del $60 \%$. En cuanto a la riqueza de especies bacterianas, los tratamientos $\mathrm{T} 1, \mathrm{~T} 3, \mathrm{~T} 4$ generaron $33,32,36$ con $6,4,3$ bandas únicas respectivamente.

A partir de estos resultados para ambos cultivos se destaca que las poblaciones bacterianas en los suelos está afectado directamente por el tipo de cultivo albergado. Esto concuerda con los reportado por (Garbeva et al. 2004) quien menciona que el tipo de planta es el factor determinante en la estructura de comunidades microbianas del suelo debido a que estos son los mayores contenedores de formas específicas de carbono y energía. Los resultados también muestran la poca variación de las poblaciones bacterianas en los suelos instalados con maíz aún en los diferentes manejos que fueron aplicados. Esto se deduce a partir de los CS por encima del 80\%. Estos resultados concuerdan con lo reportado por Ridder-Duine et al. (2005) demostrando que los cultivos de maíz no ejercen un efecto consistente en las co- 


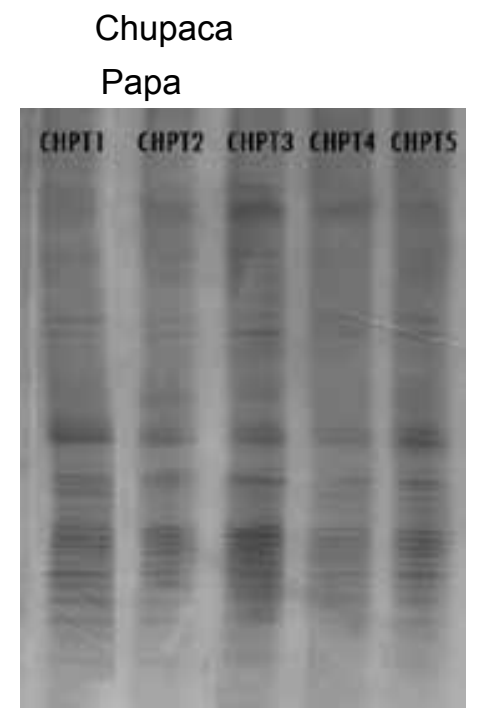

Maíz

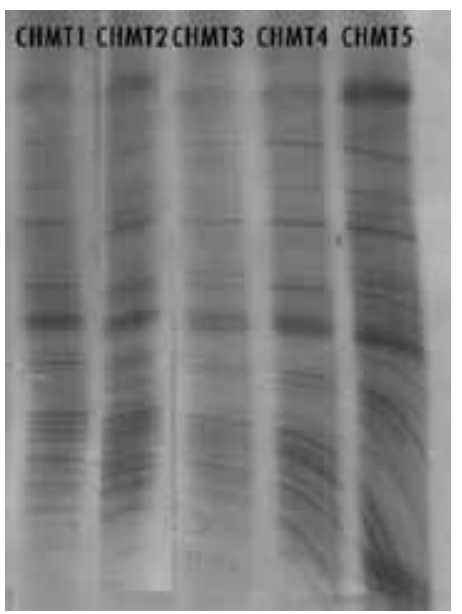

Huayao

Papa

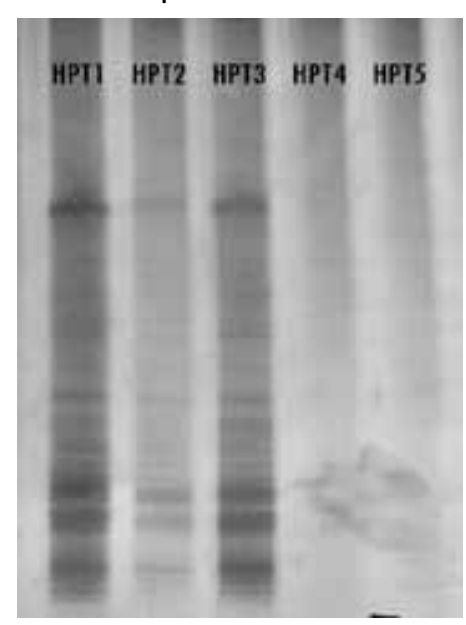

Maíz

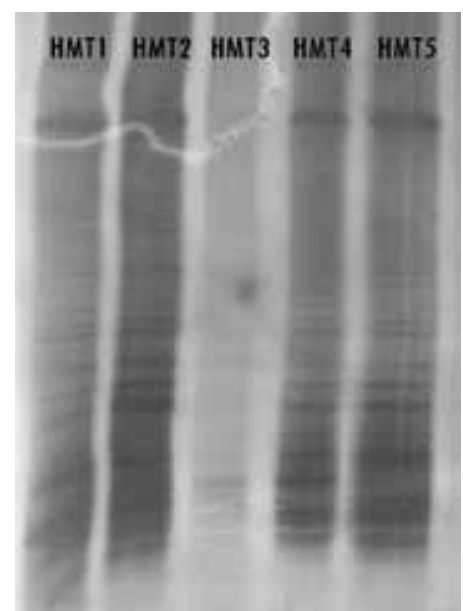

Santa Ana

Papa

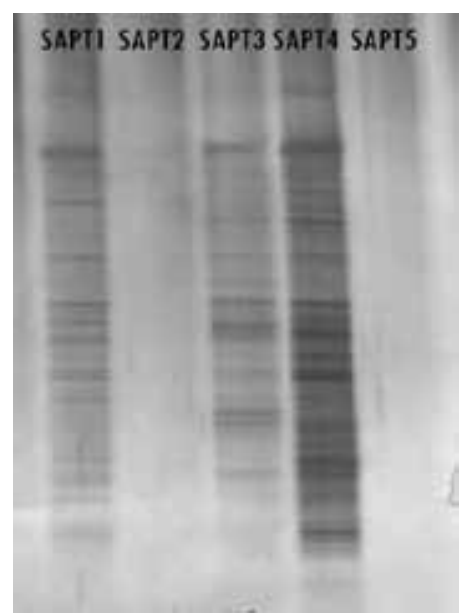

Maíz

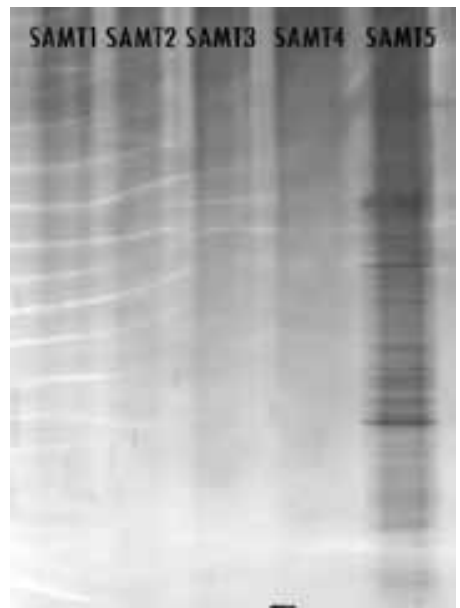

Figura 2. Geles $16 \mathrm{~S}$ rDNA-DGGE. Muestras recolectadas al término del cultivo (semana antes de cosecha). Zonas experimentales: Huayao $(H)$, Chupaca $(\mathrm{CH})$, Santa Ana (SA), Cultivos: papa (P) y maíz (M), Tratamientos: T1: ovino, T2: cuy, T3: vacuno, T4: químico, T5: testigo.

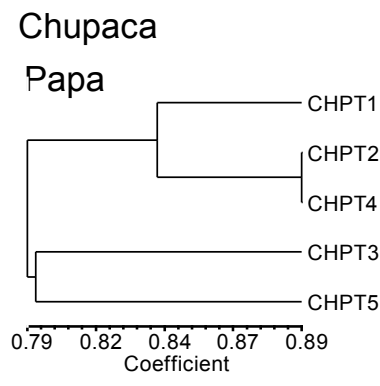

Maíz

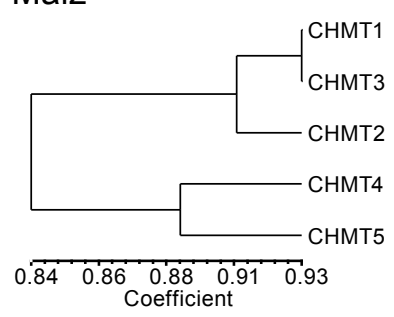

Huayao

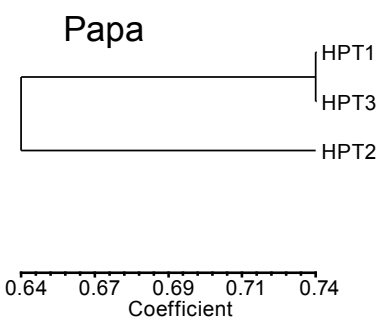

Maíz

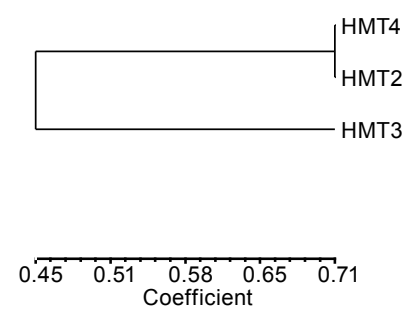

Mantaro

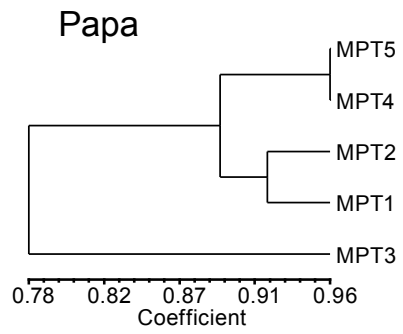

Maíz

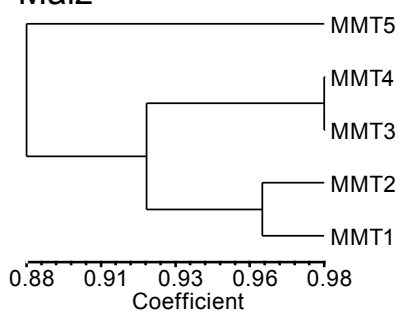

Figura 3. Análisis de poblaciones bacterianas a través de 16S rDNA-DGGE empleando iniciadores $16 S$ (968 - 1401). Dendograma generado por el algoritmo UPGMA y coeficiente de similaridad DICE. Muestras recolectadas al término del cultivo (semana antes de cosecha). Zonas experimentales: Mantaro $(\mathrm{M})$, Huayao $(\mathrm{H})$, Chupaca $(\mathrm{CH})$, Cultivos: papa $(\mathrm{P})$ y maíz $(\mathrm{M})$, Tratamientos: T1: ovino, T2: cuy, T3: vacuno, T4: químico, T5: testigo. 
munidades microbianas de su rizósfera cuando se le compara a lo largo de un amplio grupo de suelos. Este efecto no ocurre en los suelos instalados con papa en las cuales los CS están por encima del $60 \%$. Otro punto a considerar es la relación ente el tipo de fertilización con la variabilidad y abundancia de poblaciones bacterianas se ha encontrado en todos los casos un solo clusters (Chupaca) que segregan los tratamientos con fertilización orgánica de los tratamientos químicos. Con respecto a las demás zonas experimentales este efecto no resultó igual. Adeboye et al. (2006) demostraron que la fertilización química no presenta un efecto significativo sobre la biomasa microbiana del suelo, pero si la rotación del cultivo. También demostraron que el flujo de la biomasa microbiana del suelo está determinado por el $\mathrm{pH}$ y el carbono orgánico presente en el suelo. Suzuki et al. (2005) señalan además que la fertilización orgánica tiene poco impacto en las comunidades microbianas mientras que la inorgánica con amonio ejerce un fuerte efecto sobre la abundancia relativa de los diferentes grupos microbianos. Esto queda demostrado en el trabajo ya que en todos los casos se encontró que la riqueza de especies microbianas (número de bandas) en el tratamiento químico resultó estar a la par o por encima de los tratamientos con materia orgánica.

Conclusiones.- El efecto del tipo de fertilización en la dinámica poblacional de las bacterias en el suelo resultó variable para cada zona experimental y cultivo. No se ha encontrado una relación directa concluyente entre el tipo de fertilización con la distribución de las comunidades bacterianas. En lugar de ello se pudo determinar que la variabilidad de las poblaciones bacterianas en los suelos está afectado directamente por el tipo de cultivo mas no por el tipo de fertilización.

\section{Agradecimientos}

Al Programa de Ciencia y Tecnología-FINCyT por el financiamiento del presente estudio. Así mismo nuestro sincero agradecimiento a la bióloga Milagros Zavaleta Apéstegui.

\section{Literatura citada}

Adeboye, M.K.A., E.N.O. Iwuafor y J.O. Agbenin. 2006. The effects of crop rotation and nitrogen fertilization on soil chemical and microbial properties in a Guinea Savanna Alfisol of Nigeria. Plant Soil 281: 97-107.

Azevedo, J.L. 1998. Biodiversidade Microbiana e Potencial Biotecnológico. In: Melo, I.S.de e Azevedo, J.L.(ed.). Ecologia Microbiana. EMBRAPA CNPMA, Jaguariúna.

Bresolin J.D. 2006. Comparação da comunidade microbiana de solos sob vegetação nativa e sob os diferentes sistemas agrícolas em áreas de plantio comercial na região central do Cerrado. Dissertation (mestrado), Universidade de Brasília, Instituto de Ciências Biológicas http://repositorio. bce.unb.br/handle/10482/6287.

Elliott LF, Lynch JM, Papendick RI. 1996. The microbial component of soil quality. In: Stotzky G, Bollag JM (eds) Soil biochemistry. Marcel Dekker, New York, pp 1-21

EMBRAPA. (2004). Avaliação de Diversidade Microbiana em Amostras de Solos: Técnica do PCR/DGGE (Protocolo Laboratorial). Rio de Janeiro: Embrapa Solos (Embrapa Solos. Documentos, n. 68) pp 31. ISSN 1517-2627
Felipe-Morales, C., 2002. Manejo agro ecológico del suelo en sistemas andinos. En Agroecologia: el camino hacia una agricultura sustentable, Ediciones Científicas Americana, Argentina.

Garbeva, P., veen, J. A. van e Elsas, J. D. van. 2004. Microbial diversity in soil: Selection of microbial populations by plant and soil type and implications for disease suppressiveness. Annual Review of Phytopathology. 42: 243-270.

Girvan MS, Bullimore J, Pretty JN, Osborn AM, Ball AS (2003) Soil type is the primary determinant of the composition of the total and active bacterial communities in arable soils. Appl Environ Microbiol 69:1800-1809.

Griffiths, R.I., Whiteley, A.S., O’Donnell, A.G., and M.J. Bailey. 2000. Rapid method for coextraction of DNA and RNA from natural environments for analysis of ribosomal DNAand rRNA-based microbial community composition. Appl. Environ. Microb. 66:5488-5491.

Heilmann, B. Lebuhn, M. e Beese, F. 1995. Methods for investigation of metabolic activity and shifts in the microbial community in soil treated with a fungicide. Biology and Fertility of Soils. 19: 186-192.

Killham, K. 1994. Soil Ecology. Cambridge University Press, United Kingdom, pp 242.

Muyzer, G. e Smalla, K. 1998. Application of denaturing gradient gel electrophoresis (DGGE) and temperature gradient gel electrophoresis (TGGE) in microbial ecology. Antonie van Leeuwenhoek 73:127-141;

Nannipieri, P.; Ascher, J.; Ceccherini, M.T.; Landi, L.; Pietramellara, G. E Renella, G. 2003. Microbial Diversity and Soil Functions. European Journal of Soil Science 54(4):655-670

Quirino B.F., Pappas G.J., Tagliaferro A.C., Collevatti R.G., Neto E.L., da Silva M.R.S.S., Bustamante M.M.C., Kruger R.H. Molecular phylogenetic diversity of bacteria associated with soil of the savanna-like Cerrado vegetation (2009) Microbiological Research, 164 (1), pp. 59-70.

Ridder-Duine, A.S., G.A. Kowalchuk, P.J. Klein Gunnewiek, W. Smant, J.A. van Veen y W. de Boer. 2005. Rhizosphere bacterial community composition in natural stands of Carex arenaria (sand sedge) is determined by bulk soil community composition. Soil Biol. Bioch. 37: 349-357.

Seishi Ikeda, Kazuo N. Watanabe, Kiwamu Minamisawa and Nozomi Ytow (2004). Evaluation of Soil DNA from Arable Land in Japan Using a Modified Direct-extraction Method. Microbes Environ. Vol. 19, No. 4, 301-309, 2004, URL [http://wwwsoc.nii.ac.jp/jsme2/].

Silva, M. R. S., 2004: Produção de serapilheira, biomassa e diversidade de comunidades bacterianas do solo em áreas de Cerrado sob diferentes usos e manejos. M.Sc. dissertation, Departamento de Ecologia, Universidade de Brasília, 77 pp.

Suzuki, C., T. Kunito, T. Aono, C.T Liu y H. Oyaizu. 2005. Microbial indices of soil fertility. Journal of Applied Microbiology 98: 1062-1074. Alfisol of Nigeria. Plant Soil 281: 97-107. 